\title{
Synthesis, characterization and thermal decomposition kinetics of poly(2-imidazolidinthione-formaldehyde)
}

\author{
Naushad Ahmad a, Rizwan Wahab b,*, and Suliman Yousef Al Omar ${ }^{\mathrm{b}}$ \\ a Department of Chemistry, King Saud University, Riyadh 11451, Kingdom of Saudi Arabia \\ b Department of Zoology, King Saud University, Riyadh 11451, Kingdom of Saudi Arabia \\ *Corresponding author at: Department of Zoology, King Saud University, Riyadh 11451, Kingdom of Saudi Arabia. \\ Tel.: +966.53.6023284. Fax: +966.53.6023284. E-mail address: rwahab@ksu.edu.sa (R. Wahab).
}

\section{ARTICLE INFORMATION}

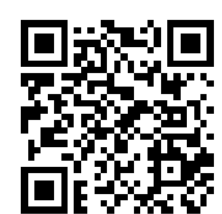

DOI: 10.5155 /eurjchem.5.1.155-161.929

Received: 21 October 2013

Received in revised form: 29 November 2013

Accepted: 30 November 2013

Online: 31 March 2014

\section{KEYWORDS}

\section{Kinetics}

Polymers

Activation energy

Polycondensation

Thermal degradation

Antibacterial activity

\section{Introduction}

The past couples of decades have witnessed an exponential growth of activities worldwide for investigating new polymers, namely polyurethane, polyester and epoxy resin with adequate properties. This has been driven both by the excitement of understanding new science and by the potential hope for applications and economic impact [1,2]. Pronounced interest has been focused on the research of organic polymers with unusual topologies and potential applications, which provide quality and safety benefits to many materials. Various researchers have revealed that the heterogeneous systems possess more economical potential and advantages over homogeneous systems [3,4]. The search for the development of high thermal resistant and biologically active polymers is on the rise to meet the growing demand of rapidly evolving high technology field. During the last decades there have been continuous and intense studies on the chemistry of heterocyclic sulphur containing compounds $[5,6]$. The importance of these compounds arises from their use as starting material for the synthesis of polymer and their possible biological implication reported $[7,8]$. The presence of heterocyclic rings in polymers improved chemical, thermal stability as well as good electrical properties. Furthermore, bis-heterocyclic have received great attention as being model compounds for many chain polymers $[9,10]$.

Formaldehyde is a building block in the synthesis of many polymers and other compounds of specialized and industrial significance. It also plays an important role as an anti-microbial agent and important precursor to many other chemical compounds. The synthesis of formaldehyde-based polymers bearing $\mathrm{N}, \mathrm{O}, \mathrm{S}$ and $\mathrm{P}$ donor groups has been an active field of research because of their ablative properties in modeling compounds, the wood industry, in coatings, composite materials $[11,12]$ and in manufacture of automobiles, and used to make components for the transmission, electrical system, engine block, door panels, axles and brake shoes.

The present manuscript reports the synthesis, spectral and thermal properties of poly(2-imidazolidinthioneformal dehyde) are discussed. The decomposition kinetics has been studied by employing Flynn-Wall-Ozawa, Friedman and Kissinger. On the other hand, polymer was selected to determine its antibacterial activity.

\section{Experimental}

\subsection{Instrumentation and materials}




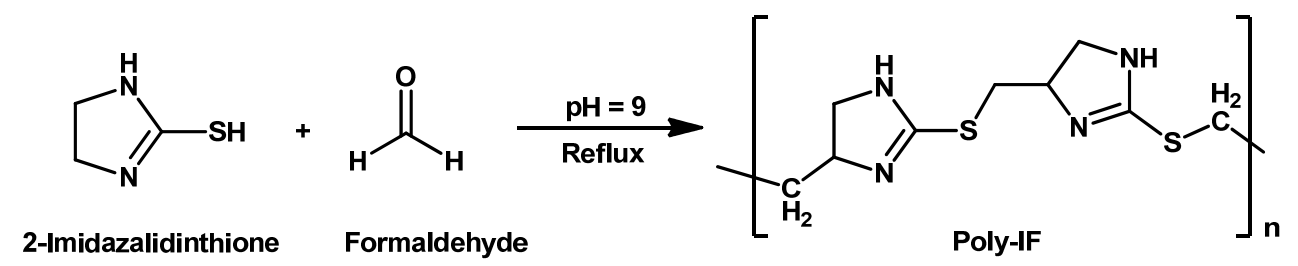

Scheme 1

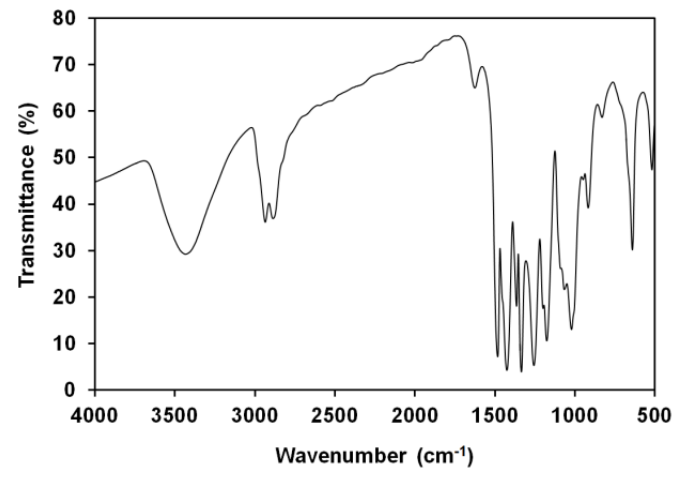

Figure 1. IR spectrum of poly-IF.

The chemicals such as 2-imidazolidinthione, formaldehyde (37\% aqueous solution), sodium hydroxide ( $40 \%$ aqueous solution) were purchased from S. D. Fine chemicals (Riyadh Saudi Arabia) and used as received. Solvents like, diethyl ether $\left(\left(\mathrm{C}_{2} \mathrm{H}_{5}\right)_{2} \mathrm{O}\right)$, dimethylformamide (DMF), dimethylsulfoxide (DMSO), chloroform $\left(\mathrm{CHCl}_{3}\right)$, trichloro-benzene $\left(\mathrm{C}_{6} \mathrm{H}_{3} \mathrm{Cl}_{3}\right)$ and tetrahydrofuran (THF) for preparation and physical measurements were obtained from Fluka and used without further purification. Elemental analysis of solid sample was performed on a Perkin-Elmer 2400 Series II, CHNS/O Analyzer. FT-IR spectra were recorded over the $4000-400 \mathrm{~cm}^{-1}$ range on a Bruker Tensor 27 FT-IR spectrophotometer by using $\mathrm{KBr}$ pellets. ${ }^{1} \mathrm{H}$ and ${ }^{13} \mathrm{C}$ NMR spectra were recorded on a JEOL-GSX 300-MHz FX-1000 FT-NMR at room temperature using DMSO$d_{6}$ as a solvent and tetramethyl silane (TMS) as an internal standard. The thermal analysis (TG/DTG) was performed using TA instruments, SDT Q-600. For each experiment, $10.0 \mathrm{mg}$ of the sample was loaded into alumina crucibles $\left(\mathrm{Al}_{2} \mathrm{O}_{3}\right)$ in the heating zone of the TGA. An empty pan was used as reference. The thermal scanning mode ranges from ambient temperature to $800{ }^{\circ} \mathrm{C}$ at a programming heating rates of $10,15,20$ and 30 ${ }^{\circ} \mathrm{C} / \mathrm{min}$ in both helium and air atmosphere with a gas flow of $100 \mathrm{~mL} / \mathrm{min}$.

\subsection{Synthesis of poly(2-imidazolidinthione-formaldehyde) (Poly-IF)}

Hot aqueous solution of 2-imidazolidinthione $(5.10 \mathrm{~g}, 0.05$ mol) was added drop wise to $37 \%$ aqueous solution of formaldehyde $(7.5 \mathrm{~mL}, 0.1 \mathrm{~mol})$ in the basic medium and the reaction mixture was refluxed for $9 \mathrm{~h}$. The reaction mixture was evaporated by a rotator and added few drops of conc. HCl. The final mixture was cooled and highly viscous condensates precipitate was obtained, which was filtered and washed with water to remove $\mathrm{NaCl}$ and then dried at $80^{\circ} \mathrm{C}$ in an oven to give the polymeric ligand. It is soluble in methanol, DMSO and DMF but insoluble in chloroform and water at room temperature. Yield: 71.87 \%. M.p: $217-218{ }^{\circ} \mathrm{C}$. Anal. calcd. for $\mathrm{C}_{9} \mathrm{H}_{14} \mathrm{~N}_{4} \mathrm{~S}_{2}$ : C, 44.60; H, 5.82; N, 23.12. Found: C, 43.28; H, 5.28; N, 22.12\%.

\subsection{Antimicrobial activity}

The growth inhabitation studies of bacteria with the poly-IF were performed using strain Escherichia coli. The strains were inoculated with $5 \mathrm{~mL}$ of freshly prepared nutrient broth medium with $50 \mu \mathrm{L}$ strain in a $15 \mathrm{~mL}$ capacity cultured glass tube. The tubes were incubated in a rotary shaker at $140 \mathrm{rpm}$ at $37^{\circ} \mathrm{C}$ for $12 \mathrm{~h}$. After the incubation the desired amount $(50$, 100,150 and $200 \mu \mathrm{g} / \mathrm{mL}$ ) poly-IF was incorporated to the bacterial suspension in the same range in all tubes $[13,14]$. The bacterial growth was monitored at every $3 \mathrm{~h}$ of regular intervals for $15 \mathrm{~h}$. The changes of absorbance were measured at $600 \mathrm{~nm}$ via a spectrophotometer (Shimadzu, UV-2550). The experiments also included a control tubes containing only media and bacteria devoid of poly-IF.

\section{Results and discussion}

The poly(2-imidazolidinthione-formaldehyde) has been synthesized by the polymerization of formaldehyde and 2imidazolidinthione in 2:1 molar ratio in alkaline medium. The analytical data agreed with the 2:1 ratio as proposed for the polymer. A slight deviation in elemental analysis may be due to the polymeric nature of the compound, as the value of end groups are not taken into account for theoretical calculation. The molecular weight of the coordination polymer could not be determined by using Gel Permeation Chromatography (GPC) technique due to their insoluble nature in solvent like trichlorobenzen and tetrahydrofuran. For all the TGA analysis curves the initial and final decomposition temperatures were variable, and the temperature increased with the heating rates, as expected. The values obtained from different methods are never identical but range closely enough to get an average value. The poly-IF was formed according to the following Scheme 1.

\subsection{Infrared spectra}

The synthesized polymer was characterized by FT-IR and their spectrum is shown in Figure 1. 
Table 1. Mass loss (\%) of poly-IF obtained from non-isothermal TG/DTG measurements in helium flow.

\begin{tabular}{|c|c|c|c|c|c|c|}
\hline Heating rate $(\beta)$ & Stage 1, \% & Stage 2, \% & Total weight loss, $\%$ & Residue, \% & $\mathrm{T}_{\max 1}\left({ }^{\circ} \mathrm{C}\right)$ & $\mathbf{T}_{\max 2}\left({ }^{\circ} \mathrm{C}\right)$ \\
\hline 10 & 18.35 & 70.51 & 88.88 & 11.34 & 288.99 & 355.59 \\
\hline 15 & 18.75 & 69.59 & 88.38 & 11.74 & 295.21 & 360.23 \\
\hline 20 & 18.16 & 68.79 & 86.95 & 13.11 & 301.34 & 366.17 \\
\hline 30 & 18.21 & 68.06 & 86.84 & 13.30 & 310.97 & 375.40 \\
\hline
\end{tabular}

Table 2. Mass loss (\%) of poly-IF obtained from non-isothermal TG/DTG measurements in air flow.

\begin{tabular}{|c|c|c|c|c|c|c|c|c|}
\hline Heating rate $(\beta)$ & Stage 1, \% & Stage $2, \%$ & Stage 3, \% & Total weight loss, $\%$ & Residue, \% & $\mathrm{T}_{\max 1}\left({ }^{\circ} \mathrm{C}\right)$ & $\mathrm{T}_{\max 2}\left({ }^{\circ} \mathrm{C}\right)$ & $\mathrm{T}_{\max 3}\left({ }^{\circ} \mathrm{C}\right)$ \\
\hline 10 & 15.62 & 47.96 & 38.25 & 100 & 0.0 & 276.66 & 339.76 & 543.45 \\
\hline 15 & 15.16 & 44.98 & 36.66 & 96.80 & 3.17 & 279.50 & 345.23 & 546.09 \\
\hline 20 & 17.65 & 50.16 & 38.96 & 100 & 0.0 & 281.02 & 348.23 & 549.18 \\
\hline 30 & 16.16 & 44.39 & 34.69 & 95.26 & 4.7 & 288.02 & 354.80 & 553.09 \\
\hline
\end{tabular}

The broad band in the region $3386 \mathrm{~cm}^{-1}$ is assigned to the stretching vibrations of $v(\mathrm{~N}-\mathrm{H})$ of the 2-imidazolidinethione which exhibit non-deprotonated [15]. The two bands appeared at 2985 and $2945 \mathrm{~cm}^{-1}$ are asymmetric and symmetric stretching vibration of methylene group [16]. A strong peak at $1485 \mathrm{~cm}^{-1}$ is due to methylene bridge associated with ring [17]. The absence of $v(\mathrm{~S}-\mathrm{H})$ band [18] at $2600 \mathrm{~cm}^{-1}$ indicate that polymerization take place via donor sulfur atom with formaldehyde and appearance of new bands at $641 \mathrm{~cm}^{-1}$ indicate the $-\mathrm{S}-\mathrm{CH}_{2}-$ band. There are bands at 1700 and 1175 $\mathrm{cm}^{-1}$ which indicate the $v(\mathrm{C}=\mathrm{N})$ and $v(\mathrm{C}-\mathrm{N})$, respectively.

\subsection{NMR analysis}

The ${ }^{1} \mathrm{H}$ NMR spectrum poly-IF showed a broad signal at $5.47 \mathrm{ppm}$ for the $\mathrm{NH}$ proton of the 2-imidazolidinthione [19]. Moreover, poly-IF exhibited signals at $3.63 \mathrm{ppm}$ due to methylene protons of $-\mathrm{S}-\mathrm{CH}_{2},-\mathrm{CH}_{2}$ ring and $3.23 \mathrm{ppm}$ due to $\mathrm{CH}$ proton of the heterocyclic ring [20]. In ${ }^{13} \mathrm{C}$ NMR spectrum, the peak observed at $183.54 \mathrm{ppm}$ and $46.03 \mathrm{ppm}$ were associated with the characteristic peak of $\mathrm{C}=\mathrm{N}$ and $-\mathrm{CH}_{2}$ of the heterocyclic ring, respectively. The chemical shifts of the cocondensed broad methylene linkage was easily observed in high field regions between 40.50-28.01 ppm, no free formaldehyde (around 80-90 ppm) was not present in any form in polymer [21]. It is also observed for both $\left({ }^{1} \mathrm{H}\right.$ and ${ }^{13} \mathrm{C}$ NMR) spectra that the solvent (DMSO- $d_{6}$ ) did not have any coordinating effect in the spectra of polymeric ligand.

\subsection{TG analysis}

The thermal behaviors of poly-IF has been studied experimentally using TG/DTG technique under helium and air atmosphere at the heating rates $10,15,20$ and $30{ }^{\circ} \mathrm{C} \mathrm{min}-$ ${ }^{1}$ shown in Table 1, 2 and Figure 2 and 3, depicted different profiles depending on heating rate and atmosphere. As evident from the figures, the polymer showed good thermal stability with no weight loss observed up to $150^{\circ} \mathrm{C}$ in both atmospheres. The non-isothermal degradation of poly-IF occurred two steps in helium and three steps in air over temperature range 50-800 ${ }^{\circ} \mathrm{C}$. In air, poly-IF became degraded leaving very small residues within the range of experimental temperature whereas, in helium, it left some residues which were found to increase in amount with increasing heating rate. The residues remaining after thermal decomposition to temperatures up to $800{ }^{\circ} \mathrm{C}$ in both atmospheres varied between 0.00 and $13.30 \%$, and are attributed to the ashes or impurities. Under the both atmosphere, the first stage of degradation between $150-300^{\circ} \mathrm{C}$, there is removal of humidity and monomer residues. The second major degradation in helium is characterized by a weight loss between $300-400^{\circ} \mathrm{C}$, which can be attributed to the evolution of most of the volatiles resulting from the depolymerization/decomposition of poly-IF and finally 400$800^{\circ} \mathrm{C}$ show char-forming reaction in the solid state whereas in air the second degradation governed by various oxidation reactions [22]. A weak DTG peak in air indicates the third stage of degradation due to charring process occurring at a relatively high temperature [23,24].

As usual, higher heating rates lead to shift the thermograms to higher temperatures. Willium et al. [25] reported that the shift in the TGA curves at higher heating rates is due to different heat transfer and kinetic rates delaying the sample decomposition. Clearly evidence of thermal decomposition was supported by DTG curves as shown in Figure $2 \mathrm{~b}$ and $3 \mathrm{~b}$. The results show a strong dependence of thermal degradation behavior of the poly-IF on the heating rate [25]. Figure $2 b$ and $3 \mathrm{~b}$ shows $\mathrm{T}_{\max }$ of the decomposition steps in DTG curve of polyIF with various heating rate increases along with the increasing of heating rate. The reason is that with the increasing of heating rate, more and more polymer is decomposed at higher temperature; that may cause the deviation from equilibrium conditions [26]. At the same heating rate, it is interesting to note that the $\mathrm{T}_{\max }$ are higher in helium than in air. Figure $2 \mathrm{c}$ and $3 c$ shows the temporal wall temperatures during TGA for the different heating rates. It is observed that the heating rate increases the time to the degradation of poly-IF decreases. Figure $2 \mathrm{~d}$ and $3 \mathrm{~d}$ shows the temporal weight losses of poly-IF at various heating rates. For each heating rate, the initial decrease in weight was due to humidity and solvents release, and the second loss was due to decomposition and depolymerization of poly-IF.

\subsection{Kinetics of thermal degradation}

The thermal stability of the poly-IF could be quantified by the activation energy of thermal degradation. The evolution of activation energy with conversion extent may provide information on mechanistic changes during thermal degradation. In the present study the activation energies for thermal decomposition were evaluated according to FlynnWall-Ozawa (FWO) [27,28], Friedman [29] and Kissinger [30] methods. These methods are well described and widely used in the literature, which provides reliable results. Therefore, these methods are selected for the kinetic analysis of the synthesized polymer.

Kinetic analysis of heterogeneous solid-state reactions always starts with the general formula for the reaction rate, $v$

$v=(d \alpha / d t)=k(T) f(\alpha)$

The quantity $\alpha$ is the degree of conversion, $t$ is the time, Tis the process temperature and $k(T)$ is a temperature-dependent rate constant and $f(\alpha)$ is a mathematical function whose form depends on the reaction type. $k(T)$ is normally approximated by the Arrhenius equation.

$k(T)=A \exp (-E / R T)$

where $E$ is the activation energy, $A$ is the pre-exponential factor and $R$ is the gas constant, $8.314 \mathrm{~J} / \mathrm{mol}$.K. This gives the basic equation (3): 

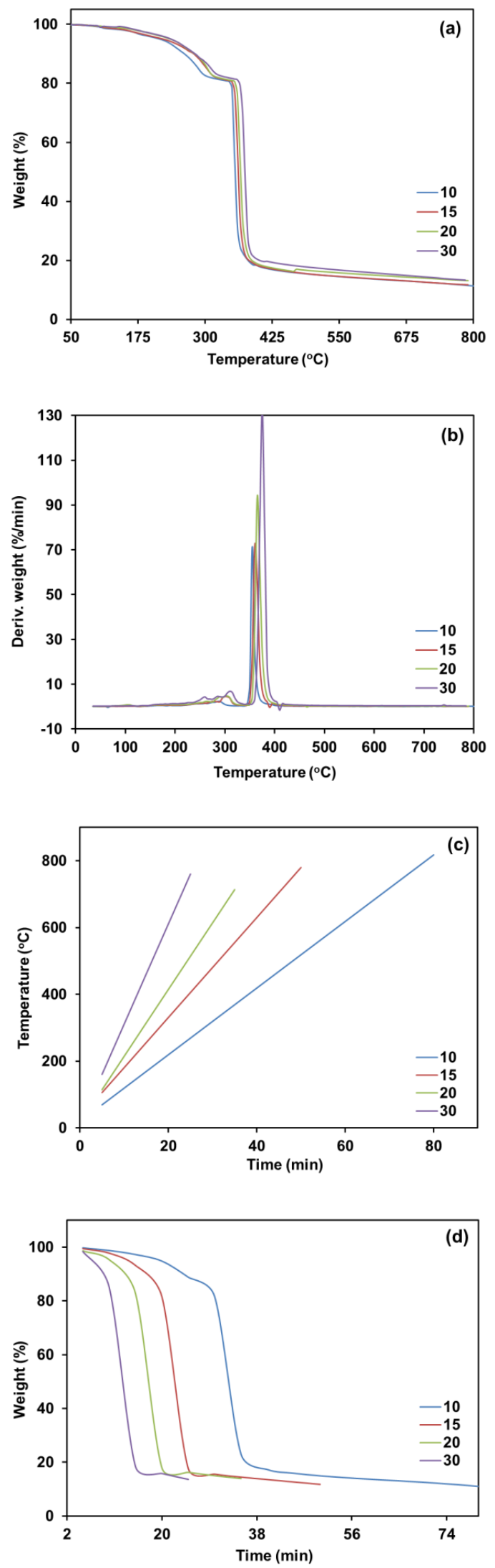

Figure 2. Thermal data of the poly-IF in Helium (a) TGA curves for the various heating rates (b) DTG curves for the various heating rates (c) Temporal variations in temperature for the various heating rates and (d) Temporal variations in weight for the various heating rates.
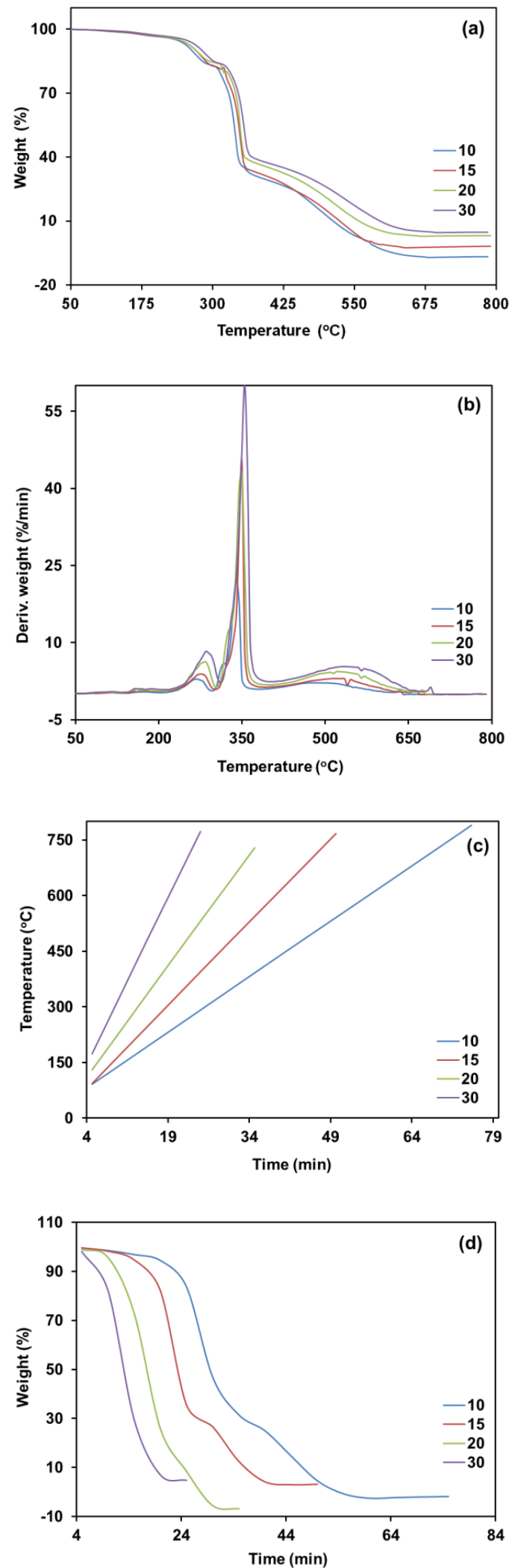

Figure 3. Thermal data of the poly-IF in Air (a) TGA curves for the various heating rates (b) DTG curves for the various heating rates (c) Temporal variations in temperature for the various heating rates and (d) Temporal variations in weight for the various heating rates. 
$(d \alpha / d t)=A f(\alpha) \exp (-E / R T)$

The FWO method determines activation energy from the weight loss versus temperature data obtained at different heating rates with equation (4):

$\ln \beta=-1.052(E / R T)+[\ln (A E / R)-\log (g(\alpha))-5.33](4)$

Being $\beta$ the heating rate. If the mechanism of the degradation process does not depend on the heating rate, then $g(\alpha)$ is constant for constant $\alpha$. The activation energy is then obtained from the slope $(-1.052 \mathrm{E} / \mathrm{R})$ of the plot of $\operatorname{Ln} \beta$ versus $1000 / T$ for any level of conversion, independent of the $g(\alpha)$ model.

The Friedman method is an isoconversional differential method based on the equation (5):

$\ln \left(\beta \frac{d \alpha}{d T}\right)=\ln A+\ln f(\alpha)-\frac{E}{R T}$

The plot $\operatorname{Ln}[\beta(d \alpha / d T)]$ versus $1000 / T$ allows evaluation of the activation energy.

The method of Kissinger uses the maximum decomposition temperature at which the rate of weight loss is the highest, no need to calculate $E$ for each conversion value in order to evaluate kinetic parameters. In this method the activation energy can be determined from equation (6):

$\ln \left(\frac{\beta}{T^{2}}\right)=\ln \left(\frac{A R}{E}\right)+\ln \left[n\left(1-\alpha_{\max }\right)^{n-1}-\frac{E}{R T_{\max }}\right.$

where $\mathrm{T}_{\max }$ is the temperature corresponding to the inflection point of the thermo degradation curves which corresponds to the maximum reaction rate, $\alpha_{\max }$ is the maximum conversion, and $n$ is the reaction order. From a plot of $\operatorname{Ln}\left(\beta / T^{2}\right)$ versus $1000 / T_{\max }$ and fitting to a straight line, the activation energy can be calculated from the slope.

In the present study four heating rates were used to evaluate activation energy. The activation energies were determined at conversions between 0.1 to 0.8 . A typical natural logarithm heating rate versus the reciprocal temperature plot at various conversion by using different methods (FWO, Friedman and Kissinger) for the constant decomposition level of poly-IF in both the atmosphere are shown in Figure 4 and 5. It shows a series of such lines created from the four curves shown in Figure 2 and 3 by plotting data at different conversion levels. Figure $4 a-c$ and 5a-c shows the linear dependence between heating rate and temperature. The isoconversional plots are parallel straight lines that indicate a complex weight loss process with several mechanisms. The slope of the lines allows calculating the activation energy. The activation energies of degradation calculated from these plots are shown in Table 3 and Figure $4 \mathrm{~d}$ and $5 \mathrm{~d}$ shows the relationship of activation energy values with the conversion extent calculated by the FWO and Friedman methods in both atmospheres. In helium flow the activation energy for low degree of conversion $(<30 \%)$ increases with advancing conversion and decreases up to $40 \%$ but after that significant increase in $E$ has been found and decreases at $80 \%$ conversion. The result shows the starting degradation reaction is due to weak bonds broken down, and the process need low energy. With the temperature increasing, some strong bonds begin to break due to transition between the first and the second step in the mass loss and its activation energy increases gradually, which indicates that the degradation becomes hard, for high degree of conversion, the char formed protects the residual compounds of further degradation [31]. It was seen that the $E$ calculated by FWO and Friedman methods for the first stage of decomposition has smaller values than for the second stage of decomposition. The activation energy of first and second stage was also calculated by the Kissinger method giving 125.07 and $171.23 \mathrm{~kJ} / \mathrm{mol}$.
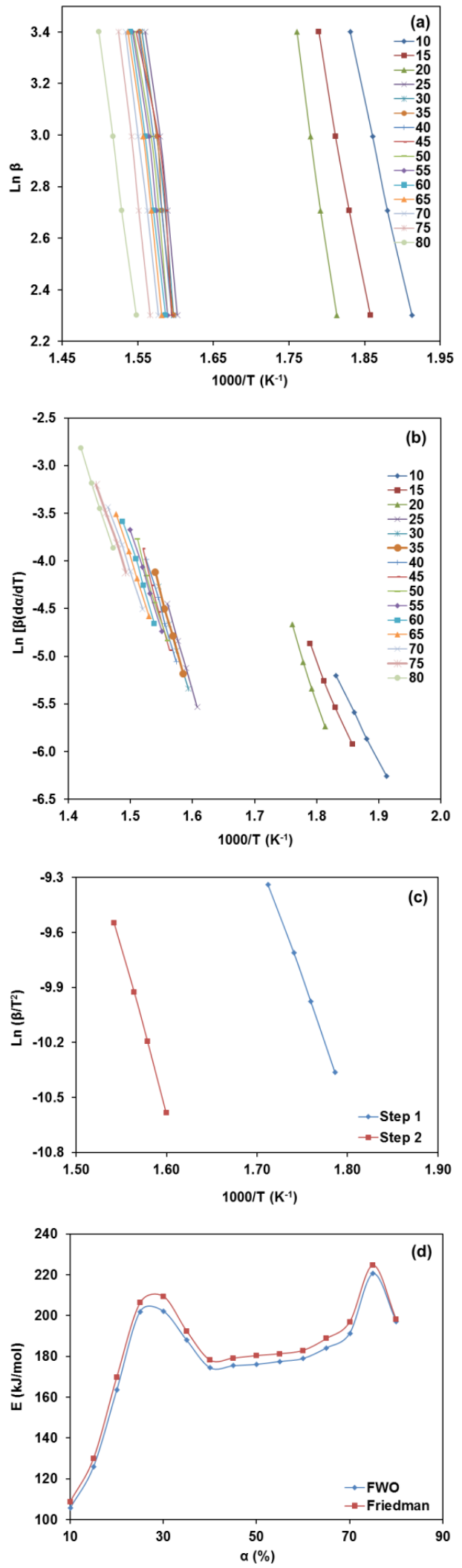

Figure 4. Evolution of activation energy at various conversions in under helium atmosphere (a) FWO plots (b) Friedman plots (c) Kissinger plots (d) Activation energies for poly-IF using the FWO and Friedman. 
Under air atmosphere, according to TGA results, poly-IF decomposes at least in three steps. In Figure 5 d, the $E$ values calculated with FWO and Friedman method for the three steps are shown together. For the first stage the $E$ increases with the increase in degree of conversion, by both methods. It is due radicals formed during the initiation reaction react rapidly with oxygen to develop a new polymer radical. For the second stage after increasing it is decreases with the increase in degree of conversion but there is slightly increase of activation energy in third stage. In other words in air atmosphere, the starting degradation activation energy is much higher and then the activation energy decreases gradually, mainly because the degradation becomes easy for oxygen participation in the later stage. These results can be explained assuming that the oxygen leads to radical formation that favors excisions in which an oxidative stage was involved as supported by complete observed mass loss. The Kissinger method gives a value of 228.10, 225.67 and $81.69 \mathrm{~kJ} / \mathrm{mol}$ for the activation energy of the first, second and third stage respectively. In air atmosphere the volatilization products are more complex than those in helium because the oxidation reaction occurring produces some oxides groups.

For effective comparison of data obtained using three methods, the mean values of activation energy for each stage were calculated as given in Table 3 . We observed that for almost all the degree of conversion investigated, the activation energies obtained by Friedman method are slightly higher as compared to those obtained with FWO method in both atmospheres. In helium atmosphere average $E$ calculated by FWO $(132.72,189.14 \mathrm{~kJ} / \mathrm{mol})$ method is very close to Kissinger method (125.07 and $171.23 \mathrm{~kJ} / \mathrm{mol}$ ). In air average activation energy for the first stage calculated by Kissinger method $(228.10 \mathrm{~kJ} / \mathrm{mol})$ significant higher than calculated by FWO $(142.93 \mathrm{~kJ} / \mathrm{mol})$ and Friedman $(145.66 \mathrm{~kJ} / \mathrm{mol})$ methods. These differences could be due to the approximation of the temperature integral that were used in the derivations of the relations that ground FWO, Friedmann methods. In addition, the average $E$ in thermo-oxidative (air atmosphere) degradation are greater than in thermal (helium atmosphere) degradation. This indicates that degradation in air results in a greater modification of the volatiles evolved during combustion than in a helium atmosphere [32-34].

\subsection{Antimicrobial activity}

The antimicrobial activity of poly-IF was tested against pathogenic strain (E. coli) at an effective conc $(50,100,150$ and $200 \mu \mathrm{g} / \mathrm{mL}$ ). It is evident from Figure 6 that the growth inhibition of $E$. coli. was prominent and conc dependent even at lower conc range $(50 \mu \mathrm{g} / \mathrm{mL})$ of poly-IF. Noticeable difference have been observed when the conc of poly-IF increases in the bacterial solution, which can be seen after $6 \mathrm{~h}$ during the logarithmic phase. The highest conc of the compound (200 $\mu \mathrm{g} / \mathrm{mL}$ ) was found to strongly inhibit the growth of all the bacterial test strains. The high anti-bacterial activity of the compound towards gram positive bacteria suggest their use as an anti-bacterial agent against preventing the spread of food poisoning and outbreaks caused by the pathogenic strains. its postulate that the poly-IF compound have attached at first to the upper membrane of the cell which has further lead to cell breakage and finally resulting in cell damage and cell lysis. This leads to the disorganized intracellular contents and have leaked out resulting in damage of the bacterial cell [35]. The studies of biochemical and enzymatic changes with the compound are needed to conclude the relation of growth inhibition activity of bacteria with compound.

\section{Conclusions}

Poly-IF was prepared by the reaction of 2-imidazolidin thione and formaldehyde in basic medium in good yield and
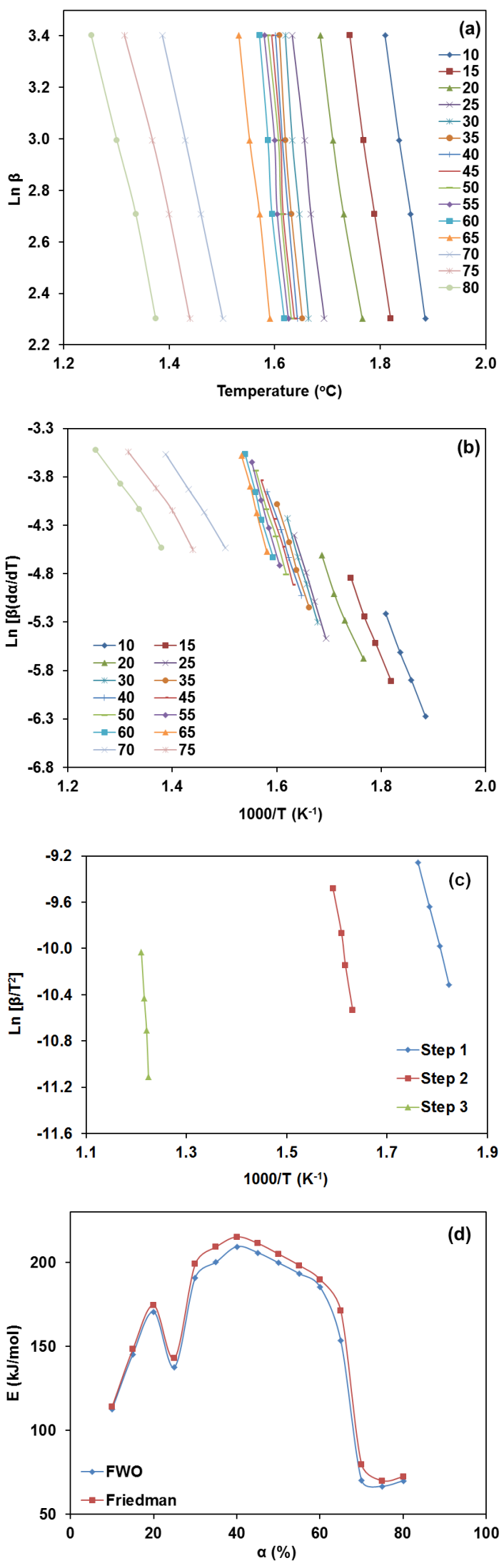

Figure 5. Evolution of activation energy at various conversions in under air atmosphere (a) FWO plots (b) Friedman plots (c) Kissinger plots (d) Activation energies for poly-IF using the FWO and Friedman. 
Table 3. Activation energy values $(\mathrm{kJ} / \mathrm{mol})$ calculated by the FWO, Friedman and Kissinger methods at varying degree of conversion.

\begin{tabular}{|c|c|c|c|c|c|c|}
\hline \multirow[t]{2}{*}{ Conversion (\%) } & \multicolumn{3}{|l|}{ In helium } & \multicolumn{3}{|l|}{ In air } \\
\hline & FWO & Friedman & Kissinger & FWO & Friedman & Kissinger \\
\hline$\overline{10}$ & 106.71 & 107.83 & 125.07 & 112.66 & 114.02 & 228.10 \\
\hline 15 & 126.90 & 128.97 & & 145.50 & 148.39 & \\
\hline 20 & 164.57 & 168.87 & & 170.63 & 174.58 & \\
\hline Mean (1 $1^{\text {st }}$ stage) & 132.72 & 135.22 & & 142.93 & 145.66 & \\
\hline 25 & 202.95 & 205.24 & 171.23 & 138.72 & 140.92 & 225.77 \\
\hline 30 & 203.14 & 208.43 & & 191.07 & 199.10 & \\
\hline 35 & 187.94 & 192.43 & & 200.24 & 209.30 & \\
\hline 40 & 174.41 & 178.19 & & 209.55 & 215.32 & \\
\hline 45 & 175.38 & 179.16 & & 205.96 & 211.53 & \\
\hline 50 & 176.48 & 180.38 & & 199.93 & 205.16 & \\
\hline 55 & 177.48 & 181.29 & & 193.45 & 198.33 & \\
\hline 60 & 178.95 & 182.93 & & 185.55 & 189.98 & \\
\hline 65 & 184.15 & 188.76 & & 153.50 & 171.37 & \\
\hline Mean (2nd Stage) & & & & 186.44 & 193.44 & \\
\hline 70 & 191.31 & 196.91 & & 70.31 & 76.01 & 81.69 \\
\hline 75 & 220.49 & 222.65 & & 66.84 & 70.05 & \\
\hline 80 & 197.10 & 197.97 & & 69.96 & 72.35 & \\
\hline Mean $\left(2^{n d}\right.$ Stage $) /\left(3^{\text {rd Stage })}\right.$ & 189.14 & 192.86 & & 69.09 & 72.80 & \\
\hline
\end{tabular}

characterized by various physicochemical methods. Mass loss is total in an oxidative atmosphere while the char yield obtained in helium at $800{ }^{\circ} \mathrm{C}$ is dependent on heating rate. We observed that the activation energies obtained by Friedman method are slightly higher as compared to those obtained with FWO method in both atmospheres. In helium flow average $E$ calculated by FWO method is very close to Kissinger method. In air $E$ for the first stage, calculated using Kissinger method, significant higher than calculated by FWO and Friedman methods. This indicates that degradation in air results in a greater modification of the volatiles evolved during combustion than in helium. Variations of $E$ values, therefore suggest a multi-step reaction mechanism. Thermal decomposition of a poly-IF is a complex, heterogeneous process, consisting of several partial reactions. The compound also has good antibacterial activity against strain $E$. coli.

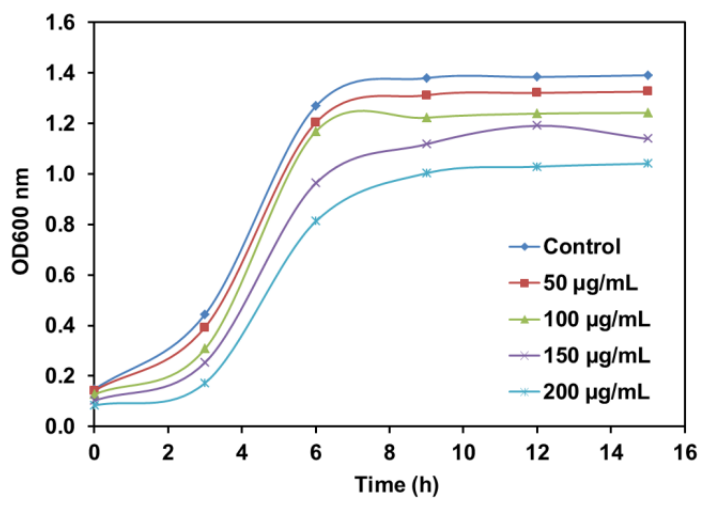

Figure 6. Bacterial growth cure of E. Coli of poly-IF.

\section{Acknowledgement}

Rizwan Wahab would like to extend the appreciation to the Deanship of Scientific Research at King Saud University for funding the work through the research group project no. RGPVPP-218.

\section{References}

[1]. Li, X.; Jiao, Y.; Li, S. Eur. Polym. J. 1991, 27, 1345-1351.

[2]. Chen, I.; Xu, H.; Yu, X.; Zhu, Y.; Yang, C. J. Polym. Sci. Part A, Polym. Chem. 1996, 34, 721-728.

[3]. Kaliyappan, T.; Kannan, T. Prog. Polym. Sci. 2000, 25, 343-347.

[4]. Yesilkaynak, T.; Binzet, G.; Emen, FM.; Florke, U.; Kulcu, N.; Arslan, H. Eur. J. Chem. 2010, 1(1), 1-5.

[5]. Yue, D.; Larock, R. C. J. Org. Chem. 2002, 67, 1905-1909.
[6]. Adams, R.D. Aldrichimica Acta 2000, 33, 39-48.

[7]. Mukherjee, C.; Kamila, S.; De, A. Terahedron 2003, 59, 4767-4774.

[8]. Binzet, G.; Florke, U.; Kulcu, N.; Arslan, H. Eur. J. Chem. 2012, 3(1), 37 39.

[9]. Finkelmann, H. Angew. Chem. Int. Ed. Eng. 1987, 26, 816-824.

[10]. Aguilera, C.; Parra, M.; Fuentes, G. Naturforsch. B 1998, 53, 367-370.

[11]. Choi, M. H.; Jeon, B. H.; Chung, I. J. Polymer 2000, 41, 3243-3252.

[12]. Choi, M. H.; Chung, I. J.; Lee, J. D. Chem. Mater. 2000, 12, 2977-2983.

[13]. Wahab, R.; Kim, Y. S.; Mishra, A. S.; Yun, Il.; Shin, H. S. Nanoscale Res. Lett. 2010, 5, 1675-1681.

[14]. Wahab, R.; Kim, Y. S.; Mishra, A.; Yun, S. Il.; Shin, H. S. Appl. Micro. Biotech. 2010, 87, 1917-1925.

[15]. Abdullah, B. H.; Salh, Y. M. Oriental J. Chem. 2010, 26, 763-773.

[16]. Kausar, A.; Zulfiqar, S.; Yavuz, C. T.; Sarwar, M. I. Polym. Degrad. Stabil. 2011, 96, 1333-1341.

[17]. Bajia, S. C.; Swarnkar, P.; Kumar, S.; Bajia, B. A E-J Chem. 2007, 4(4), 457-460.

[18]. Safavi, A.; Iranpoor, N.; Saghir, N. Sep. Purif. Technol. 2004, 40, $303-$ 308.

[19]. Shockravi, A.; Abouzari-Lotf, E.; Javadi, A. A.; Atabaki, F. Euro. Poly. J. 2009, 45, 1599-1606.

[20]. Kausar, A.; Zulfiqar, S.; Ahmad, Z.; Sarwar, M. I. Polym. Degrad. Stabil. 2010, 95, 2281-2288.

[21]. Fan, D. B.; Chang, J. M.; Li, J.; Mao, A.; Zhang, L. T. J. Appl. Polym. Sci. 2009, 112, 2195-2102.

[22]. Milena, M. C.; Dragan, B.; Renata, J.; Katarina, P. P.; Miroslav, P. Polym. Degrad. Stabil. 2003, 81, 387-392.

[23]. Sueoka, K.; Nagata, M.; Ohtani, H.; Nagai, N.; Tsuge, S. J. Appl. Polym. Sci. Part A, Polym. Chem. 1999, 29, 1903-1908.

[24]. Jin, X.; Chung, T. S. J. Appl. Polym. Sci. 1999, 73, 2195-2206.

[25]. Willium, P. T.; Besler, S. Renew Energ. 1996, 7, 233-250.

[26]. Teng, X. G.; Li, F. Q.; Ma, P. H.; Ren, Q. D.; Li, S. Y. Thermochim. Acta. 2005, 436, 30-34.

[27]. Ozawa, T. Bull. Chem. Soc. Jpn. 1965, 38, 1881-1886.

[28]. Flynn, J. H.; Wall, L. A. J. Polym. Sci. B: Polym. Lett. 1996, 4, 323-328.

[29]. Friedman, H. L. J. Polym. Sci. C 1964, 6, 183-195.

[30]. Kissinger, H. E. Anal. Chem. 1957, 29, 1702-1706.

[31]. Tao, R. M.; Xin, Li.; Yao, C. G. Front. Mater. Sci. China. 2010, 4, 78-83.

[32]. Khattab, M. A.; Price, D.; Horrocks, A. R. J. Appl. Polym. Sci. 1990, 41, 3069-3078.

[33]. Corres, M. A.; Zubitur, M.; Cortazar, M.; Mugica, A. J. Anal. Appl. Pyrol. 2011, 92(2), 407-416.

[34]. Chang, T. C.; Shen, W. S.; Chiu, Y. S.; Ho, S. Y. Polym. Degrad. Stab. 1995 49, 353-360.

[35]. Ciofi, N.; Torsi, L.; Ditaranto, N.; Tantillo, G.; Ghibelli, L.; Sabatini, L.; Zacheo, T. T.; Alessio, M. D.; Zambonin, P. G.; Traversa, E. Chem. Mater 2005, 17, 5255-5262. 